\title{
Significance of Preoperative Prone Position Computed Tomography in Free Hand Subaxial Cervical Pedicular Screwing
}

\author{
Iismail İştemen, ${ }^{1}$ Ali Arslan, ${ }^{1}$ Semih Kıvanç Olguner, ${ }^{1}$ Kemal Alper Afşer, ${ }^{1}$ Vedat Açık, Barış Arslan, ${ }^{2}$ Ali İhsan Ökten, \\ Yurdal Gezercan ${ }^{1}$ \\ Department of Neurosurgery, Adana City Education and Research Hospital, Adana, Turkey \\ Department of Anesthesia and Intensive Care, ${ }^{2}$ Adana City Education and Research Hospital, Adana, Turkey
}

Objective : The subaxial cervical pedicle screwing technique shows powerful biomechanical properties for posterior cervical fusion. When applying a pedicle screw using the freehand technique, it is essential to analyse cervical computed tomography and plan the surgery accordingly. Normal cervical computed tomography is usually performed in the supine position, whereas during surgery, the patient lies in a prone position. This fact leads us to suppose that radiological evaluations may yield misleading results. Our study aimed to investigate whether there is any superiority between preoperative preparation on computed tomography performed in the prone position and that performed in the supine position.

Methods : This study included 17 patients (132 pedicle screws) who were recently operated on with cervical vertebral computed tomography in the prone position and 17 patients (136 pedicle screws) who were operated on by conventional cervical vertebral computed tomography as the control group. The patients in both groups were compared in terms of age, gender, pathological diagnosis, screw malposition and complications. A screw malposition evaluation was made according to the Gertzbein-Robbins scale.

Results : No statistically significant difference was observed between the two groups regarding age, gender and pathological diagnosis. The screw malposition rate (from $11.1 \%$ to $6.9 \%, p<0.05$ ), mean malposition distance (from $2.18 \mathrm{~mm}$ to $1.86 \mathrm{~mm}, p<0.05$ ), and complications statistically significantly decreased in the prone position computed tomography group.

Conclusion : Preoperative surgical planning by performing cervical vertebral computed tomography in the prone position reduces screw malposition and complications. Our surgical success increased with a simple modification that can be applied by all clinicians without creating additional radiation exposure or additional costs.

Key Words : Cervical vertebrae · Pedicle screws · Computed tomography · Prone position.

- Received : August 27, 2020 •Revised : September 25, 2020 •Accepted : October 28, 2020

- Address for reprints : İsmail İ̧̧temen

Department of Neurosurgery, Adana City Education and Research Hospital, Dr. Mithat Özsan Bulvarı Kışla Mah. 4522 Sok. No:1, Yüreğir/ADANA 01230, Turkey

Tel : +90-322 45590 00, Fax : +90-0322 34403 05, E-mail : drismailistemen@gmail.com, ORCID : https://orcid.org/0000-0002-2341-4818

This is an Open Access article distributed under the terms of the Creative Commons Attribution Non-Commercial License (http://creativecommons.org/licenses/by-nc/4.0) which permits unrestricted non-commercial use, distribution, and reproduction in any medium, provided the original work is properly cited. 


\section{INTRODUCTION}

The subaxial cervical posterior pedicle screwing technique provides a powerful construct in stabilising the cervical vertebrae ${ }^{13-15,28)}$. It also gives extreme manoeuvrability in correcting vertebral deformities. However, screw malposition can lead to severe complications due to the neural and vascular structures adjacent to the vertebrae. Therefore, its routine use is still limited $^{4)}$. Instrument sizes and entrance angles can vary from patient to patient. There is no defined standard technique ${ }^{3,4,12)}$. To avoid screw malposition and complications, navigation-assisted surgery, sensing and seeing the pedicle with micro-laminotomies and careful analysis of preoperative computed tomography (CT) are recommended ${ }^{5,7,30)}$.

Neuronavigation-assisted surgery significantly reduces screw malposition ${ }^{19,29)}$. However, limitations such as serious cost increase, prolonged surgical time, loss of surgical skills and restriction of training the assistants have been report$\mathrm{ed}^{6,16,19,21,24,29)}$. Studies have reported that it increases screw malposition, although rare ${ }^{17,20)}$. It also causes high-dose radiation exposure for both the patient and the surgeon.

With the freehand surgical technique, exposure to radiation is reduced and surgery duration is shortened ${ }^{22,31)}$. In this technique, scope is limited to the posterior-anterior and lateral radiographs only after the screws are placed. Screw application in the freehand technique is planned according to anatomical landmarks. Pathologies secondary to surgery, such as osteophytic changes in degenerative cases and post-laminectomy kyphosis, cause difficulties in identifying anatomic landmarks and surgical application. Therefore, in the freehand surgical technique, it is essential to evaluate the anatomical structure of patients with preoperative CT.

Standard cervical CT is performed in the supine position. In surgery, the patient lies in the prone position with head flexion. This leads us to suppose that radiological evaluations can yield misleading results, especially in screw angles and, therefore, in screw lengths (Fig. 1). In our study, we aimed to investigate whether the preoperative preparation performed on CT in the prone position is superior to that in the supine position.

\section{MATERIALS AND METHODS}

This retrospective chart review study involving human participants was in accordance with the institutional and national research committee's ethical standards and with the $1964 \mathrm{Hel}-$ sinki Declaration and its later amendments or comparable ethical standards. The Human Investigation Committee (IRB : 806, date : 2020 April 22) of Adana City Education and Re-
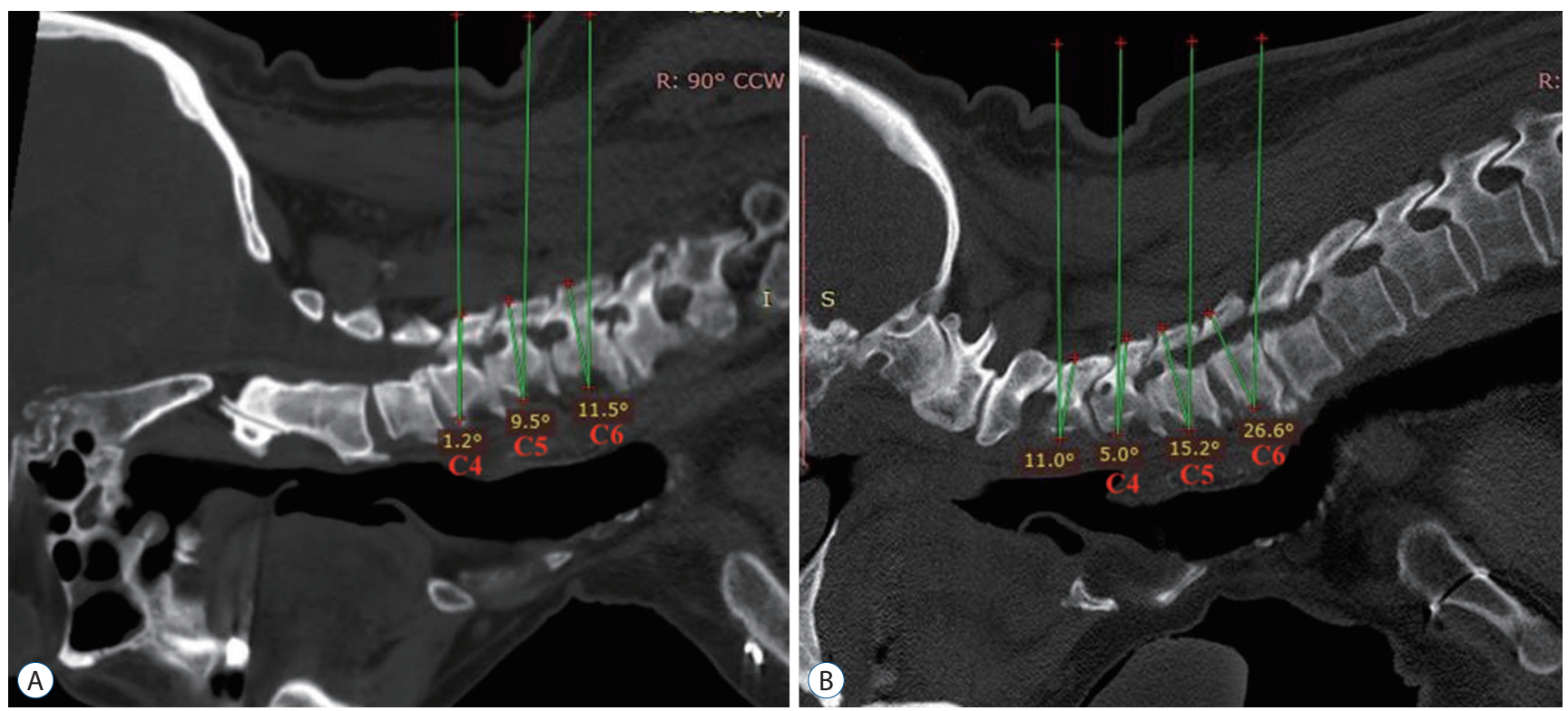

Fig. 1. The same patient's computed tomography sagittal sections. A : Supine position. B : Prone position. The angles between the vertical line and the pedicle plane appear to increase from $11.5^{\circ}$ to $26.6^{\circ}$ at the $\mathrm{C} 6$ level, from $9.5^{\circ}$ to $15.2^{\circ}$ at the $\mathrm{C} 5$ level and from $1.2^{\circ}$ to $5^{\circ}$ at the $\mathrm{C} 4$ level. 
search Hospital approved this study.

Patients who underwent posterior subaxial cervical pedicle screwing for degenerative and traumatic deformities, spondylotic and multilevel stenosis, discopathy and oncological pathologies from 2014 to 2019 were scanned in our clinic. Sixtyseven patients who were applied with 512 pedicle screws were detected. Seventeen patients (132 pedicle screws) who underwent prone position CT, which is the position given to the patients during the operation, and who were operated on with preoperative preparations accordingly, and 17 patients (136 pedicle screws) who conventionally underwent supine position CT and who were operated on with preoperative prepara- tion (136 pedicle screws) accordingly were included in the study. The patients were classified into the supine position CT group and the prone position CT group. Twenty-eight patients with 196 screws operated on in the first year of performing the technique were not included in the study because of negative results due to the learning curve. Moreover, five patients with a pedicle diameter smaller than $3 \mathrm{~mm}$ were excluded from the study. The same surgical procedure was applied to the patients by the same surgical team. The patients in both groups were compared in terms of age, gender and pathological diagnosis. The development of neurovascular injury due to screw malposition was investigated. Postoperative CT evaluation was
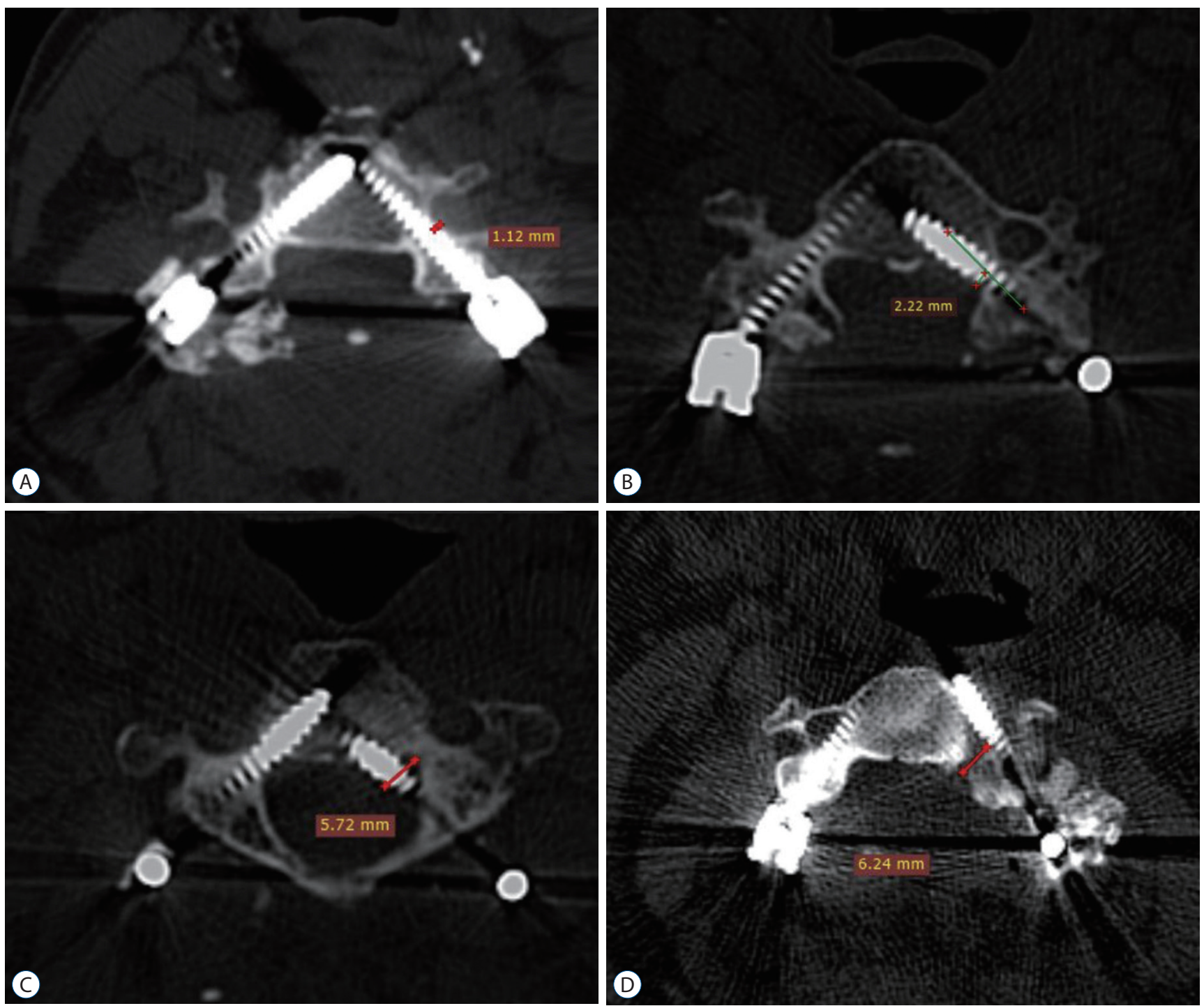

Fig. 2. Post operative computed tomography evaluation according to the Gertzebein-Robbins scale. A : Grade A on right pedicle and grade B on left pedicle. B : Grade C on left pedicle. C: Grade D on left pedicle. D: Grade E on left pedicle. 
made according to the Gertzbein-Robbins scale (Fig. 2) ${ }^{10)}$. The Gertzbein-Robbins scale is evaluated in Table 1.

During the CT examination, the patient is taken in the Concorde position, similar to during surgery. The body is raised by placing a silicone pillow under the breast and the neck is flexed. The head of the patient is fixed by tapes, similar to during surgery (Fig. 3).

The pedicle perforation distance was measured as the nominal in screw malposition. Radiological evaluations were screened by three different observers.

\section{Surgical technique}

We performed the technique as reported by Abumi ${ }^{1)}$. The patient was placed in the Concorde position. Muscle dissection was performed up to the lateral margin of the lateral mass. The optimal entry point for the $\mathrm{C} 3-\mathrm{C} 7$ pedicles was chosen as slightly lateral to the centre of the articular mass and close to the inferior margin of the inferior articular process of the cranially adjacent vertebra. The entry points were slightly modified according to the CT anatomy of each patient. We determined the medial and vertical angles and screw size according to the evaluations made on the CT scan. A small cortical funnel-like-shaped hole was drilled with a highspeed burr with a diamond tip. The cancellous bone was passed by sensing the medial wall with the curved probe. As

\section{Table 1. Gertzebein-Robbins scale}

\begin{tabular}{ll}
\hline Grade A & Screw in proper position \\
Grade B & Penetration of less than $2 \mathrm{~mm}$ \\
Grade C & Penetration of more than 2, but less than $4 \mathrm{~mm}$ \\
Grade D & Penetration of more than 4 , but less than $6 \mathrm{~mm}$ \\
Grade E & Penetration of more than $6 \mathrm{~mm}$ \\
\hline
\end{tabular}
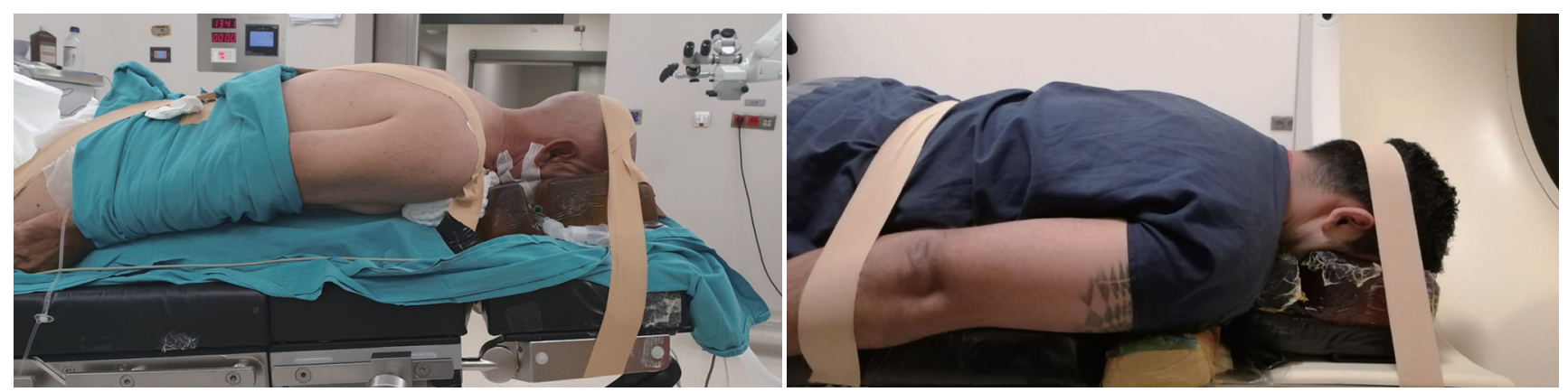

Fig. 3. Positioning during surgery and computed tomography examination. the medial wall is the thickest, it is not easy to penetrate with a pedicle probe. After tapping and controlling with a ball tip probe, the appropriate size screw was placed. Anterior-posterior and lateral radiographs were viewed by an intraoperative C-arm.

\section{Statistical analysis}

The demographic characteristics of the patients and surgical characteristics were summarised using descriptive statistics. The Kolmogorov-Smirnov test was used to check whether continuous variables were normally distributed. The chisquare test was also used. We used the IBM SPSS ver. 22 program (IBM Corp., Armonk, NY, USA) for the statistical analysis in our study. The Wilcoxon signed-rank test was used to compare the surgical treatment results. We compared the groups according to the Kruskal-Wallis test. The significance value for this study was set to $p<0.05$. The Mann-Whitney $U$ test was used in the pairwise comparisons of the groups. Kendall's coefficient of concordance (Kendall's W) test was used in the SPSS program to evaluate the agreement between the measurements of independent observers. The range of values was $0-1$, which indicates an excellent agreement as it approaches 1 .

\section{RESULTS}

No significant difference was found between the two groups in terms of age and gender characteristics. The surgical pathologies of the patients were found to be similar. In both groups, the most common pathology was cervical stenosis, and the second most common pathology was traumatic lesions (Tables 2 and 3).

Kendall's coefficient of concordance (Kendall's W) test was 
used in the SPSS program to evaluate the agreement between the measurements of independent observers. The interobserver reliability showed excellent agreement with an intraclass correlation coefficient of 0.994 .

Screw malposition with CT was evaluated separately for each cervical segment according to the Gertzbein-Robbins scale. Grade A and B are considered successful and grade C-E as unsuccessful. The malposition rate was found to be higher at the $\mathrm{C} 3$ level in both groups than at other levels $(p<0.05)$. Malposition at the C3 level in the prone position CT group was statistically significantly lower than in the supine position CT group $(p<0.05)$. The success rate for each level is given in

Table 2. Evaluation of the groups in terms of age and gender

\begin{tabular}{lccc}
\hline & $\begin{array}{c}\text { Supine position } \\
\text { CT group }\end{array}$ & $\begin{array}{c}\text { Prone position } \\
\text { CT group }\end{array}$ & p-value \\
\hline Avaerage age (years) & 49.70 & 50.47 & $>0.05$ \\
Minimum & 22 & 28 & \\
Maximum & 66 & 66 & \\
Gender & & & \\
Male & 10 & 11 & $>0.05$ \\
Female & 7 & 6 & \\
\hline
\end{tabular}

$\mathrm{CT}$ : computed tomography

Table 3. Distribution of pathological diagnoses within the groups

\begin{tabular}{lcc}
\hline & $\begin{array}{c}\text { Supine position } \\
\text { CT group }\end{array}$ & $\begin{array}{c}\text { Prone position } \\
\text { CT group }\end{array}$ \\
\hline Cervical spinal stenosis & 7 & 6 \\
Trauma & 4 & 4 \\
Oncological & 3 & 3 \\
Kyphotic deformity & 2 & 3 \\
Multilevel discopathy & 1 & 1 \\
\hline
\end{tabular}

$\mathrm{CT}$ : computed tomography

Table 4. Success rate for each cervical segment and Mann-Whitney $U$ test for screw malposition between the groups

\begin{tabular}{lcccccc} 
& \multicolumn{2}{c}{ Success rate (\%) } & & \multicolumn{2}{c}{ Mann-Witney U } \\
\cline { 2 - 3 } \cline { 5 - 6 } & Supine group & Prone group & & $\mathbf{U}$ & $\boldsymbol{p}$-value \\
\hline C3 & 83.3 & 90.0 & & 1224 & $<0.05$ \\
C4 & 90.9 & 93.5 & & 1845 & $<0.05$ \\
C5 & 90.3 & 92.8 & & 1845 & $<0.05$ \\
C6 & 88.2 & 93.5 & & 1845 & $<0.05$ \\
C7 & 90.9 & 95.4 & & 1224 & $<0.05$ \\
\hline
\end{tabular}

Table 4. The total successful screw rate was $88.9 \%$ in the supine position CT group and $93.1 \%$ in the prone position CT group. The screws in both groups were successful in terms of malposition, according to the Wilcoxon signed-rank test $(\mathrm{Z}=-8.973, p<0.005)$. According to the statistically performed Mann-Whitney $\mathrm{U}$ test $(\mathrm{U}=1224, p<0.05)$, screw success in the prone position in terms of screw malposition was significantly higher between the groups (Table 4). When the screw malposition was evaluated numerically, the average screw penetration was $2.18 \mathrm{~mm}$ in the supine position CT group and 1.86 $\mathrm{mm}$ in the prone position CT group, which was statistically significantly lower $(p<0.005)$.

In the supine position CT group, two patients had C5 palsy, and one patient had vertebral artery (VA) occlusion. Whereas complete recovery was achieved in one of the patients who developed C5 palsy, loss of strength was permanent in the other patient. There were no severe clinical complications due to VA occlusion. Transient C5 palsy was detected in two patients in the prone position CT group.

\section{DISCUSSION}

Subaxial cervical screw placement using the freehand technique has been increasingly used as the standard method since Abumi et al.'s description in 1994'. However, complications include severe neurovascular injuries. It has been emphasised in the literature that these complications are an essential factor making the technique difficult ${ }^{2,4,17,19}$. CT-guided navigation systems can be used to perform surgery with the least error. Despite its positive results, it leads to high-dose radiation exposure for both the patient and the surgeon. Moreover, it extends the surgery time, is expensive and inaccessible, restricts surgical abilities and creates disadvantages for trainee physicians ${ }^{6,24}$. Despite all these limitations, it reduces screw malposition below $10 \%{ }^{8}$. Articles have reported that it increases screw malposition, albeit rare ${ }^{17,20)}$. CT-based navigation cannot provide real-time navigation, and intraoperative spinal alignment changes can appear during patient positioning. In our technique, the patient's CT scans are evaluated in the prone position closest to the operation position. Our technique is inexpensive, simple and fast, and it provides satisfactory results similar to the CT-based navigation system.

To avoid malposition, the screw can be inserted by feeling 
the pedicle with mini-laminotomies, but it creates difficulties in multilevel operations. Moreover, sensing the medial wall may not be sufficient to avoid lateral injuries. For this reason, it is not a standard practice in the freehand technique. Burcev et al. ${ }^{8)}$ reported that critical screw malposition rate around $40 \%$ with this technique. This value is considerably higher than that in our series. Nevertheless, it is suitable for use in suspicious cases in terms of assistance. In the literature, the rate of failed screw-in cervical pedicle screws used with different techniques has been reported at varying rates of 1.1-29.8\%. In the series reported in recent years, the rate of failed screws did not exceed $10 \%{ }^{8,9)}$. Preoperative CT examinations are the most important and frequently used kind of assistance. When making preoperative measurements by taking the preoperative CT in the prone position, which is the patient's position during surgery, more accurate screw trajectories and screw sizes can be chosen. Thus, the rate of failed screws in our series decreased from $11.1 \%$ to $6.9 \%$. The screw was applied successfully following the literature, but the success rate increased through the simple change we used.

Previous studies have described different entry points and different medial angles ${ }^{3,8,12,35)}$. Medial angulation between 25$50^{\circ}$ has been reported in various methods ${ }^{1,2,5,22,27,36)}$. This wide range of medial angulation is also related to the choice of entry point. As the entry point slides laterally, the medial angulation increases ${ }^{2,18,27,33)}$. It is necessary to capture the normal anatomical angle of this pedicle. To reduce the malposition rate, anatomical landmarks should be correctly identified on preoperative CT, and the correct entry point selection should be made. The medial wall is the most robust in the pedicle wall, and the medial wall penetration of the screw is less common. Many studies have focused on lateral wall injury and have even used stratification according to lateral wall penetration alone to assess screw malposition ${ }^{23,27,32)}$. Moreover, VA injury can be observed with lateral wall injury. Therefore, avoiding lateral wall injury is important, but inferior and superior wall penetrations are also crucial for neural injury. In this context, sagittal angulation is considered significant. In the current knowledge, sagittal angulation has not been emphasised in studies. Our study concluded that screw sagittal angulations, which are similar to the surgical position, decreased screw malposition in the prone position CT group. Patients are usually operated on in the prone position with head flexion. Changing the lordosis angles of the patients in this posi- tion will affect the sagittal angulation. Moreover, although many authors describe the entry point differently, it is generally defined as 1-2 mm inferior to the facet joint. Owing to the separation of the facet joint space in the prone position, errors may develop in determining the entry point. In this case, errors are expected in screw angulations in the sagittal and axial planes. In our study, we performed preoperative evaluations and measurements on the CT scans performed in the prone position, as this would be the patient's position during the surgery. This avoided additional radiation exposure and did not create extra costs. We found a significant decrease in the number of malposed screws and the mean malposition distance between the two groups.

The number of VA injuries reported in the literature is $0-2.4 \%{ }^{23,25,27)}$. Spinal nerve root damage was reported at a rate of $0-8.3 \%$ in the review by Yoshihara et al. ${ }^{33)}$, in which complications were screened. There was no spinal cord injury in our study. As a significant permanent complication, C5 palsy was detected in only one patient in the supine position CT group. Transient C5 palsy was observed in one patient, and it completely healed in the follow-up. One patient had VA occlusion, but no clinical findings occurred, and thus screw revision did not need to be performed. Transient C5 palsy was observed in two patients in the prone position CT group, and it completely healed in the follow-up. There were no major permanent complications in the prone position CT group. Both groups were compatible with the literature in terms of complications, but the results were better in the prone position CT group. Even a single complication can sometimes be severe in this technique, and thus complications should be reduced as much as possible with the least error.

According to the literature, as the pedicle width of the C6C7 vertebra is large, malposition is less at these levels. On the contrary, as the pedicle of the $\mathrm{C} 3-\mathrm{C} 4$ vertebrae is thin, malposition develops more frequently at these levels ${ }^{11,17,26)}$. In our series, the highest malposition rate was found at the $\mathrm{C} 3$ level in both groups. At the C3 level in the prone position CT group, the malposition rate was significantly lower than in the other group. The lowest rate of malposition at the C7 level was detected in the prone position CT group. We considered the increase in success to be mainly related to the accuracy in sagittal angles. However, there was still a high malposition at the C3 level, consistent with the literature. This is because the pedicle is anatomically thin, and the muscles attached to the $\mathrm{C} 2$ verte- 
bra are usually not dissected thin enough to preserve stability.

It is a difficult technique and is not included in primary training programs in many neurosurgery clinics. Therefore, there is a learning process. The results vary significantly when using this technique, depending on the learning curve ${ }^{23,34)}$. To prevent this situation, the first 28 patients were not included in our study. Further, to shorten the learning process, attending practical courses on cadavers or models is recommended, and anatomical structures should be well known. Preoperative radiological examinations should be well analysed, and surgical planning should be individual. In this way, the learning process can be accelerated.

The same surgical procedure was applied to all the patients by the same surgical team. The patient groups were homogeneous in terms of age, gender and required pathological diagnosis.

This study is limited by the fact that it was conducted with small patient groups. Studies with more extensive series should give more reliable results. Prospective comparative studies of surgical planning created through preparation with prone position CT and CT-guided surgical techniques will enable us to reach a more precise conclusion.

\section{CONCLUSION}

As it is the patient's position during surgery, preoperative surgery planning with CT in the prone position provided positive results regarding screw malposition and complications in the freehand subaxial cervical pedicle screwing technique. The surgical success in this study increased with a simple change that could be applied by all clinicians without creating additional radiation exposure or costs incurred by patients.

\section{CONFLICTS OF INTEREST}

No potential conflict of interest relevant to this article was reported.

\section{INFORMED CONSENT}

Informed consent was obtained from all individual participants included in this study.

\section{AUTHOR CONTRIBUTIONS}

\author{
Conceptualization : Iİ, KAA, SKO \\ Data curation : VA, SKO \\ Formal analysis : $\mathrm{BA}$ \\ Methodology : Iİ, AA \\ Project administration : İं, YG \\ Visualization : KAA, AA \\ Writing - original draft : III, KAA \\ Writing - review \& editing : İ̈, AIÖ
}

\section{ORCID}

İsmail İștemen https://orcid.org/0000-0002-2341-4818

Ali Arslan https://orcid.org/0000-0002-7457-5283

Semih Kivanç Olguner https://orcid.org/0000-0002-5314-4636

Kemal Alper Afşer https://orcid.org/0000-0002-4724-0840

Vedat Açık https://orcid.org/0000-0002-0371-5883

Barış Arslan https://orcid.org/0000-0001-9386-514X

Ali İhsan Ökten https://orcid.org/0000-0003-0292-201X

Yurdal Gezercan https://orcid.org/0000-0002-4124-2036

\section{References}

1. Abumi K : Cervical spondylotic myelopathy: Posterior decompression and pedicle screw fixation. Eur Spine J 24 Suppl 2 : 186-196, 2015

2. Abumi $K$, Ito $M$, Sudo $H$ : Reconstruction of the subaxial cervical spine using pedicle screw instrumentation. Spine (Phila Pa 1976) 37 : E349-E356, 2012

3. Abumi $\mathrm{K}$, Itoh $\mathrm{H}$, Taneichi $\mathrm{H}$, Kaneda $\mathrm{K}$ : Transpedicular screw fixation for traumatic lesions of the middle and lower cervical spine: description of the techniques and preliminary report. J Spinal Disord 7 : 19-28, 1994

4. Abumi K, Shono Y, Ito M, Taneichi H, Kotani Y, Kaneda K : Complications of pedicle screw fixation in reconstructive surgery of the cervical spine. Spine (Phila Pa 1976) 25 : 962-969, 2000

5. Ando K, Imagama S, Ito Z, Kobayashi K, Ukai J, Muramoto A, et al. : Unilateral instrumented fixation for cervical dumbbell tumors. J Orthop Surg Res $9:$ 2, 2014

6. Aoude AA, Fortin M, Figueiredo R, Jarzem P, Ouellet J, Weber MH : Methods to determine pedicle screw placement accuracy in spine surgery: a systematic review. Eur Spine J 24 : 990-1004, 2015

7. Bayley E, Zia Z, Kerslake R, Boszczyk BM : The ipsilateral lamina-pedicle angle: can it be used to guide pedicle screw placement in the sub-axial cervical spine? Eur Spine J 19 : 458-463, 2010 
8. Burcev AV, Pavlova OM, Diachkov KA, Diachkova GV, Ryabykh SO, Gubin AV : Easy method to simplify "freehand" subaxial cervical pedicle screw insertion. J Craniovertebr Junction Spine 8 : 390-395, 2017

9. Celikoglu E, Borekci A, Ramazanoglu AF, Cecen DA, Karakoc A, Bektasoglu PK : Posterior transpedicular screw fixation of subaxial vertebrae: accuracy rates and safety of mini-laminotomy technique. Asian J Neurosurg $14: 58-62,2019$

10. Gertzbein SD, Robbins SE : Accuracy of pedicular screw placement in vivo. Spine (Phila Pa 1976) 15 : 11-14, 1990

11. Herrero CF, Luis do Nascimento A, Maranho DAC, Ferreira-Filho NM, Nogueira CP, Nogueira-Barbosa MH, et al. : Cervical pedicle morphometry in a latin american population: a Brazilian study. Medicine (Baltimore) 95 : e3947, 2016

12. Hojo $Y$, Ito M, Suda $K$, Oda I, Yoshimoto $H$, Abumi $K$ : A multicenter study on accuracy and complications of freehand placement of cervical pedicle screws under lateral fluoroscopy in different pathological conditions: CT-based evaluation of more than 1,000 screws. Eur Spine J 23 : 2166-2174, 2014

13. Hostin RA, Wu C, Perra JH, Polly DW, Akesen B, Wroblewski JM : A biomechanical evaluation of three revision screw strategies for failed lateral mass fixation. Spine (Phila Pa 1976) 33 : 2415-2421, 2008

14. İştemen İ, Arslan A, Olguner SK, Gezercan Y, Ökten Ail, Afşer KA : The effect of straight or lordotic rods on cervical subaxial alignment while fusing C1-C2. World Neurosurg 133 : e653-e657, 2020

15. Istemen I, Ozdogan S, Duzkalır AH, Senturk S, Yıldırım T, Okutan MO : Clinical results of median corpectomy in cervical spondylotic patients with myelopathy. Turk Neurosurg 26 : 90-96, 2016

16. Ito $H$, Neo M, Yoshida M, Fujibayashi S, Yoshitomi $H$, Nakamura T : Efficacy of computer-assisted pedicle screw insertion for cervical instability in RA patients. Rheumatol Int 27 : 567-574, 2007

17. Kast E, Mohr K, Richter HP, Börm W : Complications of transpedicular screw fixation in the cervical spine. Eur Spine J 15 : 327-334, 2006

18. Kim HB, Lee MK, Lee YS, SoHn JY, Jung SK, ParK JH : An assessment of the medial angle of inserted subaxial cervical pedicle screw during surgery: practical use of preoperative CT scanning and intraoperative Xrays. Neurol med Chir (Tokyo) 57 : 159-165, 2017

19. Kotani $Y$, Abumi $K$, Ito M, Minami A : Improved accuracy of computerassisted cervical pedicle screw insertion. J Neurosurg 99 (3 Suppl) : 257-263, 2003

20. Kothe R, Rüther W, Schneider E, Linke B : Biomechanical analysis of transpedicular screw fixation in the subaxial cervical spine. Spine (Phila Pa 1976) 29 : 1869-1875, 2004

21. Kotil K, Bilge $T$ : Accuracy of pedicle and mass screw placement in the spine without using fluoroscopy: a prospective clinical study. Spine J 8 : 591-596, 2008

22. Lee DH, Lee SW, Kang SJ, Hwang CJ, Kim NH, Bae JY, et al. : Optimal entry points and trajectories for cervical pedicle screw placement into subaxial cervical vertebrae. Eur Spine J 20 : 905-911, 2011

23. Lee S, Seo J, Lee MK, Jeon SR, Roh SW, Rhim SC, et al. : Widening of the safe trajectory range during subaxial cervical pedicle screw placement: advantages of a curved pedicle probe and laterally located starting point without creating a funnel-shaped hole. J Neurosurg Spine 27 : 150157, 2017

24. Mason A, Paulsen R, Babuska JM, Rajpal S, Burneikiene S, Nelson EL, et al. : The accuracy of pedicle screw placement using intraoperative image guidance systems. J Neurosurg Spine 20 : 196-203, 2014

25. Nakashima H, Yukawa Y, Imagama S, Kanemura T, Kamiya M, Yanase M, et al. : Complications of cervical pedicle screw fixation for nontraumatic lesions: a multicenter study of 84 patients. J Neurosurg Spine 16 : 238-247, 2012

26. Oh SH, Min WK : Analysis of cervical pedicle with reconstructed computed tomography imaging in Korean population: feasibility and surgical anatomy. J Spinal Disord Tech 27 : E99-E103, 2014

27. Park JH, Jeon SR, Roh SW, Kim JH, Rhim SC : The safety and accuracy of freehand pedicle screw placement in the subaxial cervical spine: a series of 45 consecutive patients. Spine (Phila Pa 1976) 39 : 280-285, 2014

28. Pelton MA, Schwartz J, Singh K : Subaxial cervical and cervicothoracic fixation techniques--indications, techniques, and outcomes. Orthop Clin North Am 43 : 19-28, vii, 2012

29. Richter M, Cakir B, Schmidt R : Cervical pedicle screws: conventional versus computer-assisted placement of cannulated screws. Spine (Phila Pa 1976) 30 : 2280-2287, 2005

30. Tofuku K, Koga H, Komiya S: Cervical pedicle screw insertion using a gutter entry point at the transitional area between the lateral mass and lamina. Eur Spine J 21 : 353-358, 2012

31. Urbanski W, Jurasz W, Wolanczyk M, Kulej M, Morasiewicz P, Dragan $S L$, et al. : Increased radiation but no benefits in pedicle screw accuracy with navigation versus a freehand technique in scoliosis surgery. Clin Orthop Relat Res 476 : 1020-1027, 2018

32. Wang Y, Xie J, Yang Z, Zhao Z, Zhang Y, Li T, et al. : Computed tomography assessment of lateral pedicle wall perforation by free-hand subaxial cervical pedicle screw placement. Arch Orthop Trauma Surg 133 : 901-909, 2013

33. Yoshihara H, Passias PG, Errico TJ : Screw-related complications in the subaxial cervical spine with the use of lateral mass versus cervical pedicle screws: a systematic review. J Neurosurg Spine 19 : 614-623, 2013

34. Yoshimoto H, Sato S, Hyakumachi T, Yanagibashi Y, Kanno T, Masuda T : Clinical accuracy of cervical pedicle screw insertion using lateral fluoroscopy: a radiographic analysis of the learning curve. Eur Spine J 18 : 1326-1334, 2009

35. Zhang ZF : Freehand pedicle screw placement using a universal entry point and sagittal and axial trajectory for all subaxial cervical, thoracic and lumbosacral spines. Orthop Surg 12 : 141-152, 2020

36. Zheng X, Chaudhari R, Wu C, Mehbod AA, Transfeldt EE : Subaxial cervical pedicle screw insertion with newly defined entry point and trajectory: accuracy evaluation in cadavers. Eur Spine J 19 : 105-112, 2010 